\title{
Reimagining the Higher Education Experience as a Socially-Enabled Complex Adaptive System
}

\author{
Munir Mandviwalla \\ Temple University \\ Munir.Mandviwalla@temple.edu
}

\author{
David Schuff \\ Temple University \\ David.Schuff@temple.edu
}

\begin{abstract}
Higher education faces challenges on many fronts, including new learning models such as MOOCs, new forms of credentialing that question the value of a diploma, and a generation of students raised on socially-enabled technologies that view creating and sharing information differently. Clearly change must occur, but existing siloed models are well-ingrained into the culture. In this paper, we use complex adaptive systems theory to go inside the "black box" of higher education to envision how socially-enabled technologies can transform processes, roles, and behaviors of key internal and external agents. We describe two new models: (1) Continuous Development, which places students in direct control of their own professional development and (2) Co-Creation, which makes students an integral part of knowledge generation and dissemination. We analyze the changes in traditional structures and interactions these models bring, and propose design principles that guide the design IT systems that enable these changes.
\end{abstract}

\section{Introduction}

Higher education is at a crossroads and faces major competitive challenges [6]. Regional monopolies are being eroded by satellite and online programs and the introduction of new products such as low cost certificates. IT has for the last decade played a major role in the disruption and transformation of many industries. Yet, the role of IT in traditional universities and colleges is stagnant and focuses on automating isolated processes (e.g., a new recruiting system). Even new entrants that are free of constraints of established personnel and structures, focus on applying IT to automate and scale the same time honored model of hierarchical, rule-based, sequential, and siloed education. The application of IT to achieve scale and reach will likely allow these new entrants to take market share away from existing institutions but it will not improve the quality of higher education. We will end up with providers of similar products that have questionable value in the future and who can only compete on cost and access. Cost and scale are important but to be relevant in the 21 st century, improving quality and relevance is equally important.

We believe higher education is much more than just a series of factories that apply the same procedures to produce identical goods. Delors et al. [4, p. 37], asserted that "formal education systems tend to emphasize the acquisition of knowledge to the detriment of other types of learning; but it is vital now to conceive education in a more encompassing fashion." A key differentiating element of the US higher education system is enabling connections and communities locally and worldwide. It is about relationships, serendipity, and the vigorous debate, generation, and exchange of ideas. This 'experience' is ignored by IT that focuses on automating courses as instances of (only) extant knowledge acquisition and dissemination. MOOCs, lecture video capture, learning management systems, and online delivery platforms only focus on scaling and improving access to siloed knowledge transmission. This is now a century old 'innovation' that started when universities constructed large lecture halls and organized education into packaged blocks of courses. IT can play a much more transformative role in higher education by focusing on the experience that enables institutions to differentiate and compete on quality. Further, focusing on the experience plays to the strengths of established institutions rather than new entrants.

In this paper, we 'go inside the firm' and analyze the higher education value chain as a complex adaptive system to identify key structures, behaviors, and flows. We apply CAS to design new IT enabled models that can leverage and further improve the experience of higher education.

\section{Literature review}

Information systems, education, management, and providers of educational technology all study the use of IT in higher education from different perspectives and provide important findings on how to improve the educational process based on different 
levels of abstraction including individuals, courses, programs, and colleges.

Information systems research has primarily focused on the application of technological tools (e.g., group decision support systems) to improve learning. In this research, the unit of analysis is usually at the individual level. There has also been research on the macro role of IT (e.g., [17]) and the use of IT to address recruitment and retention issues in IS.

There is an extensive body of research in education that has analyzed the education process from multiple perspectives. The use of IT in education has focused on improving the learning process in the form of Computer Aided Instruction (CAI), the development and use of administrative systems (e.g., recruiting), as well as case studies that apply new technologies to achieve local wins (e.g., using Twitter inside a class). Overall, in education research the use of IT focuses on the use of individual modern technologies at the individual or course level, while program and institutional level research tends to ignore new technologies such as social media and instead focuses on the application of transaction processing systems to improve administrative efficiency.

Several management and public policy scholars have studied higher education. Christensen and Eyring [2] predict a major disruption in higher education from new entrants and increased competition, while Smith [15] analyzes how institutions' pricing power is eroding. However, these macro-economic and competitive analyses of change do little to provide guidance on how to move forward.

The educational technology industry has put forward many new interesting innovations. However, these systems directly replicate extant structures (e.g., Blackboard, Institutional Web Sites, administrative systems) or have the potential to create new structures but are still framed in terms of existing structures (e.g., Edmodo), limiting their utility.
The organization-centric, process-oriented approach of Information Systems (IS) is a strength in considering the transformational role of IT in higher education. IS has a long tradition of empirical, process improvement, and multidisciplinary research on important educationally relevant technologies such as decision making, organization design, ecommerce, computer-mediated communication (CMC), electronic meeting systems, virtual teams, and increasingly social media. We offer a process perspective, focusing as much on how an outcome is achieved as the outcome itself. Taking a prescriptive process perspective regarding technology design and use can lead to new transformative strategies. In short, IS has an opportunity to directly influence one of the most important pillars of society - higher education. In the subsequent sections, we apply a process aware, outcome oriented, multi-level, and contingent technology approach to study higher education.

\section{Complex Adaptive Systems}

Figure 1 provides a high level process centric and institutional view of higher education. Students are recruited through a variety of tactics (e.g., Facebook ads, phone calls from alums, broadcast advertising) and then admitted following an increasingly complex decision making process (e.g., discounting, grants, demographics, size of class). The educational process broadly consists of a series of courses ('teach') and extra-curricular professional development activities ('develop'). At the end of the educational process, students follow various approaches to select and secure a career, and then finally institutions try to engage alums for connections (e.g., placement), resources (donations), and goodwill (e.g., build reputation). The above process flows through the traditional hierarchy of institutions consisting of administrative offices, and colleges with deans, majors, departments, and classes.

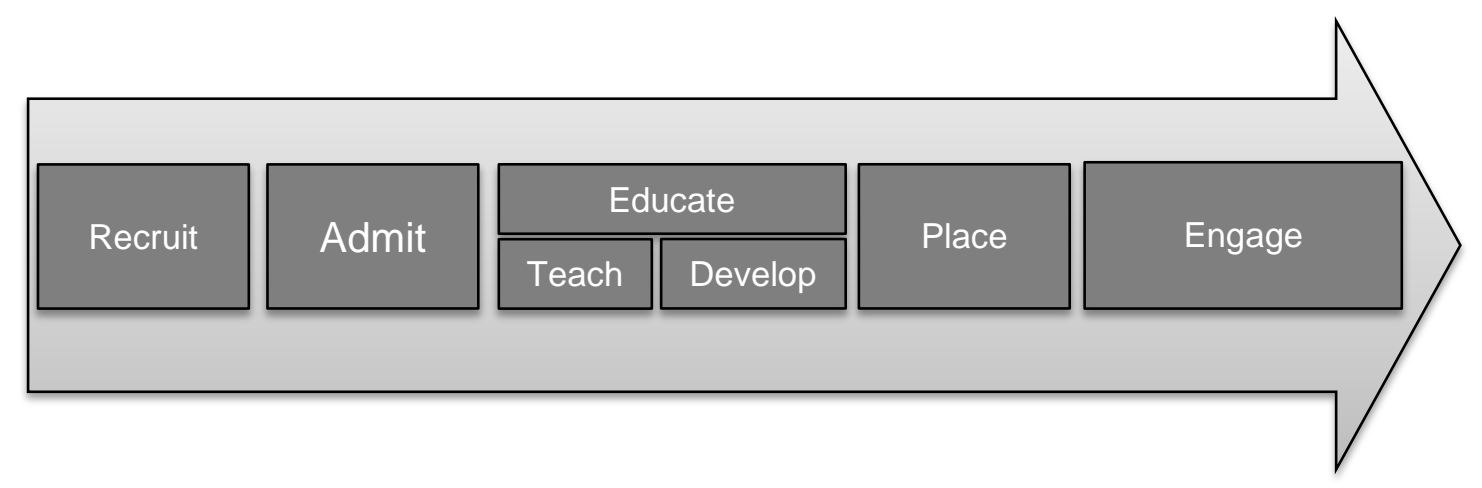

Figure 1. Higher Education Value Chain 
In the above, students do belong to specific colleges, majors, departments, and classes but they are not static entities, and actively and frequently choose and change these affiliations based on convenience, friends and family, finances, and changing preferences. They navigate, conform, bend, and adapt to the rules and structures as independent agents to take the classes they want, grow personally, and seek employment. The student today is increasingly characterized by ad-hoc communication, multi-tasking, and collaborative work interspersed with collaborative play; they are digital natives [16] and their lebenswelt (lifeworld) is social, mobile, open, and defined by ubiquitous access and use of information. Similarly, faculty report to deans but they are also independent actors who teach, research, and act based on their interests and in relation to their academic discipline and network - the "invisible college." It is this focus that determines their behavior and interaction patterns.

The traditional hierarchical view is thus incomplete. It cannot fully explain the achievements of the U.S. higher education system that continues to churn out Nobel laureates, new ideas, new innovations, and new businesses. Complex Adaptive Systems (CAS) theory can shed new light into the interaction among the agents of higher education and their relationships to illustrate existing best practices and pinpoint levers for technology-enabled change. CAS is "composed of interacting agents described in terms of rules. The agents adapt by changing their rules as experience accumulates" $[9$, p. 10]. CAS theory can go inside the seemingly highly hierarchical outer shell of higher education and analyze a more nuanced reality to leverage the peer-to-peer under-structure instead of focusing only on the traditional one-to-many overstructure. CAS focuses on people and their interactions which are arguably the most important actors in higher education.

The theory of complex adaptive system (CAS), which is increasingly applied in diverse areas such as management [1], healthcare [13], and information systems [12] thus provides a powerful conceptual lens to study higher education from the IS perspective. According to Nan [12], the uses and consequences of IT "are often enacted through self-orchestrated interactions among users, technologies, and institutional properties rather than dictated by organizational policies or managerial intentions." (p. 505). By focusing on the most critical elements of higher education: people (agents), interactions such as knowledge sharing, mentoring, feedback, and the environment which constrains and enables these activities, CAS can:

- Identify the attributes, behaviors, and relationships that influence both individual (e.g., student) and collective (institutional) patterns and outcomes.

- Trace process improvements over time in the educational value chain.

- Uncover or design emergent structures that can effect major change.

Since CAS focuses on systems that evolve, it can trace process improvements over time in the educational value chain depicted in figure 1. Finally, the theory can design and uncover new processes that arise from the natural or technology enabled interactions of the agents in the context of top-down institutional goals such as recruitment, education, and placement. Table 1 outlines the basic concepts of CAS as applied to higher education.

\section{Table 1. Basic CAS Concepts and Higher Education} (adapted from [12])

\begin{tabular}{|c|c|c|}
\hline Concept & Description & Example \\
\hline Agent & $\begin{array}{l}\text { Individual actors or } \\
\text { basic entities of } \\
\text { actions }\end{array}$ & $\begin{array}{l}\text { Students, faculty, } \\
\text { administrative units, courses, } \\
\text { IT }\end{array}$ \\
\hline Attribute & $\begin{array}{l}\text { Internal states of } \\
\text { agents }\end{array}$ & $\begin{array}{l}\text { GPA, maturity, interaction } \\
\text { style }\end{array}$ \\
\hline $\begin{array}{l}\text { Behavioral } \\
\text { rule }\end{array}$ & $\begin{array}{l}\text { Schemata that } \\
\text { govern attributes } \\
\text { and behaviors of } \\
\text { agents }\end{array}$ & $\begin{array}{l}\text { When to ask questions, how to } \\
\text { motivate }\end{array}$ \\
\hline Interaction & $\begin{array}{l}\text { Mutually adaptive } \\
\text { behaviors }\end{array}$ & $\begin{array}{l}\text { Case discussion, large class } \\
\text { dynamics }\end{array}$ \\
\hline Connection & $\begin{array}{l}\text { Relational links } \\
\text { among agents }\end{array}$ & $\begin{array}{l}\text { Friendships, membership in } \\
\text { student organization }\end{array}$ \\
\hline Flow & $\begin{array}{l}\text { Movements of } \\
\text { resources }\end{array}$ & $\begin{array}{l}\text { Ideas, knowledge, dress code } \\
\text { for interview, job leads }\end{array}$ \\
\hline Environment & $\begin{array}{l}\text { Medium for agents } \\
\text { to operate on and } \\
\text { interact with }\end{array}$ & $\begin{array}{l}\text { Educational institution and its } \\
\text { educational, recruitment, } \\
\text { placement, knowledge } \\
\text { production, development goals }\end{array}$ \\
\hline Structure & $\begin{array}{l}\text { Topography of } \\
\text { environment and } \\
\text { relationship to } \\
\text { agents }\end{array}$ & $\begin{array}{l}\text { Departmental structure, major } \\
\text { structure, college structure, } \\
\text { financial services structure }\end{array}$ \\
\hline
\end{tabular}

Figure 2 presents a generic CAS model of IT use and design in higher education and is adapted from 


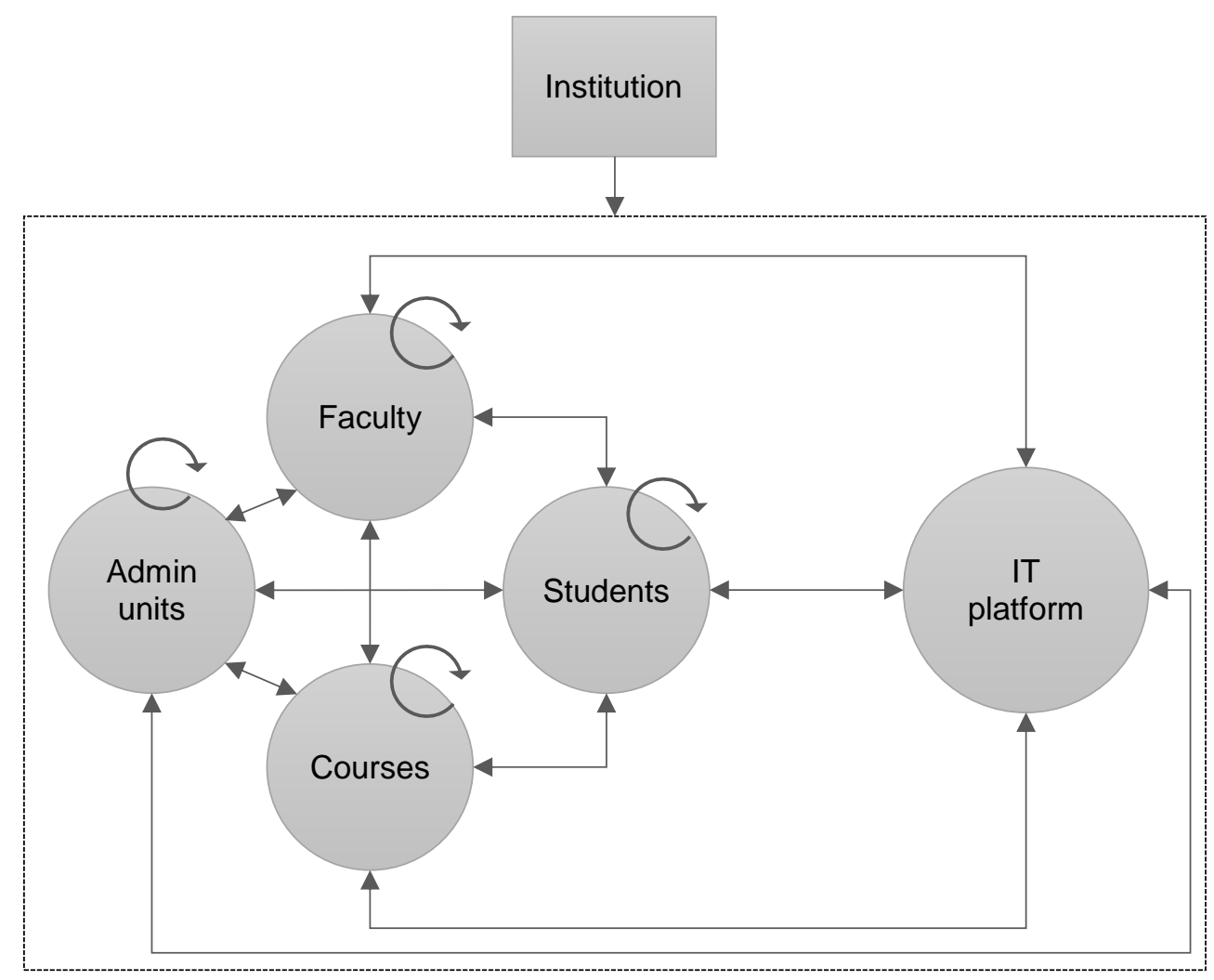

Figure 2. CAS model of IT design and use in higher education

Nan's generic model of IT use [12]. The institution provides the environmental - social and organizational - context in the form of extant structures and their properties. The institution sets the educational and administrative goals that should be embedded into the features of the platform which constrains and enables interaction among the agents. The institutional goals include typical items such as recruitment, high quality education, placement, and building a reputation. Faculty, students, courses, and administrative units are internal agents that instantiate institutional goals such as teaching, taking courses, studying, advising, and grading. The arrows in figure 2 show the connections and flow of knowledge, documents, feedback among the agents, while the circular arrows on top of each agent represents the interaction within each agent type. Interaction with external agents such as employers, prospective students, parents, and alumni is omitted for ease of representation.

\section{Design}

In this section, we describe the design of a social IT platform based on the above CAS model for IT design and use in higher education. The CAS model provides the conceptual and architectural backdrop for the social IT platform. The social IT platform is comprehensive and is designed to replace traditional institutional websites as well as 'learning management systems.' The social aspects of the platform are important in higher education because first, social media is easy to use, familiar, and can naturally fit the lifeworld of the major agent (students). Second, unlike other technologies, the focus of social media is people, the most important resource and product of higher education. Third, the salient characteristic of social media - interactivity increases and changes the connections and resource flows among agents. This can lead to new, transformative structures and outcomes that enhance and leverage the peer-to-peer structure of higher education.

The Community platform is a Web 2.0 cloud hosted platform based on WordPress, an open source content management system, and BuddyPress, a social plug-in that adds member profiles, avatars, friending, groups, and private messaging (available at http://community.mis.temple.edu). The platform includes a customized look and feel relevant to higher education, custom developed plugins (e.g., gradebook, leaderboards, e-portfolio wire, e-portfolio 
search, e-portfolio badges), templates (for course and e-portfolio creation), and tutorials. All content including courses, members, and the individual sites of each member including their profiles, e-portfolios, and activities are open and accessible over the Internet. All members are content generators and aggregators while white pages (profiles), internal messaging, site wide activity "wires", chat, and commenting support interaction and discovery.

The institutional goals of the platform include recruitment, high quality education, placement, and building a reputation. Faculty, students, courses, and administrative units are internal agents that instantiate institutional goals such as teaching, taking courses, studying, advising, and grading. Every student, faculty, and staff member create and maintain their online brand through an "e-portfolio" site. Each course is a separately managed site, and members can create additional sites (e.g., projects). Instructors post lectures, announcements, as well as interactive questions on the platform. The open content promotes conversations and sharing. For example, students compare and use content across sections of the same course even when the instructors are different. The site-wide activity feed on the front page (similar to the Facebook news feed) fuels additional interaction. In the feed, all sites get equal "billing" including student managed sites. Members update their profiles to indicate their interests as well as job status, and the changes are pushed to the community, while instructors' use commenting, rating, and voting to sustain interaction.

As of May 2013, the platform had more than 5450 registered members, over 4200 sites, and $1100+$ approved e-portfolios. It had hosted 13,796 posts, 35,386 comments, and more than 250 courses. According to Google Analytics, it had 30,000-35,000 unique visitors per month, 9,000 from the local domain (the rest were external); 55 percent were new each month. The platform is typically ranked in the top three for Google searches on "MIS."

Table 2 describes the four key design principles of the platform (open, individual control, discovery, and aggregation) in the context of CAS. The attributes, behavioral rules, interactions, and flows of these models are described as specific technology characteristics, functionalities, user-system interactions and links, and the movement of IT enabled resources [12]. In the remainder of this paper, we focus on the design of two new sub-models that correspond to the 'teach' and 'develop' boxes in figure 1. These models are derived from CAS principles and are designed to transform the development and placement of students and bring in new resources and modalities of instruction into teaching. Table 3 summarizes the key design propositions of each model in the context of underlying behavioral mechanisms as well as measurement and justification criteria. The table focuses on the individual level. At the macro institutional level, the models are intended to increase placement, institutional reputation, and the quality of educational experience. We next describe each model in detail.

\subsection{Continuous development model}

Traditionally, student professional development and placement is characterized by a series of isolated and sequential interactions such as a student submits their resume to employers, career services distributes job postings, and a faculty member provides mentorship about careers. The new continuous development model changes how students develop, network, and seek jobs into a continuous process. Figure 3 contrasts the two approaches by applying the longitudinal agent - interaction lens of CAS.

The key artifact in the model is the e-portfolio, a living collection of documents that showcase a student's achievements and establishes a digital identity. Beyond a basic template for formatting and some guidelines, students maintain high individual control. Students have complete and sole control over their e-portfolio content. A typical e-portfolio includes sample projects, internship descriptions, posts about current events, and media such as pictures and video. The fundamental change brought on by e-portfolios is that they provide a richer way to communicate identity than paper resumes and can be updated regularly and in near real-time, residing on a server that is accessible anytime and anyplace.

Regular check points ensure that students continuously develop their e-portfolio. Students are required to create an e-portfolio in the first course of their major. Subsequent courses generate new relevant content (e.g., projects). Aggregation ensures that activities such as starting an e-portfolio, submission to the official e-portfolio search engine, and changes to profile fields show as notifications on the site's main page. The entire community is energized by each new e-portfolio or update notification. Further, discovery mechanisms ensure community members can read, reference, and comment on each e-portfolio. For example, students will post positive comments on a particularly informative e-portfolio site or link directly to that content. That site will quickly gain visibility and become a model for others when comments show up on the site-wide activity feed or appear as embedded URLs elsewhere on the site. 
Table 2. Applying CAS to design

\begin{tabular}{|c|c|}
\hline \multicolumn{2}{|l|}{ Design Principle: Open } \\
\hline $\begin{array}{l}\text { Attributes and } \\
\text { Functionalities }\end{array}$ & $\begin{array}{l}\text { Structures and } \\
\text { Interactions }\end{array}$ \\
\hline $\begin{array}{l}\text { - Resources and } \\
\text { agents are public (e.g., a } \\
\text { new post in a course is } \\
\text { automatically published } \\
\text { on the Internet, a widget } \\
\text { displays 'who is online'). } \\
\text { - New agents and } \\
\text { resources can be added } \\
\text { by any internal or } \\
\text { external agent (e.g., an } \\
\text { external agent posts a } \\
\text { comment in a course or } \\
\text { on a e-portfolio) }\end{array}$ & $\begin{array}{l}\text { • } \quad \text { Form new structures } \\
\text { by redirecting resource } \\
\text { flows (e.g., a student } \\
\text { who accepts a job at a } \\
\text { firm becomes their } \\
\text { recruiter and uses e- } \\
\text { portfolio search to } \\
\text { identify candidates for } \\
\text { additional openings). } \\
\text { - Sidestep existing } \\
\text { structures and alters } \\
\text { connections among } \\
\text { agents (e.g., faculty and } \\
\text { career services are no } \\
\text { longer intermediaries } \\
\text { between internal agents- } \\
\text { students and external } \\
\text { agents-employer). } \\
\text { - Breaks down } \\
\text { existing structures by } \\
\text { enabling resource flows } \\
\text { to go across boundaries } \\
\text { (e.g., students review } \\
\text { content from multiple } \\
\text { sections of the same } \\
\text { course). }\end{array}$ \\
\hline \multicolumn{2}{|c|}{ Design Principle: Individual Control } \\
\hline $\begin{array}{l}\text { Attributes and } \\
\text { Functionalities }\end{array}$ & $\begin{array}{l}\text { Structures and } \\
\text { Interactions }\end{array}$ \\
\hline $\begin{array}{l}\text { - Agents directly and } \\
\text { independently generate } \\
\text { resources (e.g., create } \\
\text { and own a new blog) } \\
\text { - Agents retain } \\
\text { attribution and control } \\
\text { over their resources (e.g., } \\
\text { a post is tied to its } \\
\text { author, and can be } \\
\text { edited, reposted) } \\
\text { - Agents control their } \\
\text { identity and interactions } \\
\text { (e.g., decide what to } \\
\text { reveal on e-portfolios, } \\
\text { and on profile fields) }\end{array}$ & $\begin{array}{l}\text { - Create new rules for } \\
\text { managing resources (e.g., } \\
\text { students learn to directly } \\
\text { manage the quality of } \\
\text { their digital identity) } \\
\text { Agents generate and } \\
\text { share resources directly } \\
\text { creating new flows (e.g., } \\
\text { student-student, student- } \\
\text { external agent, and } \\
\text { external-agent-faculty). }\end{array}$ \\
\hline \multicolumn{2}{|c|}{ Design Principle: Discovery ('pull') } \\
\hline $\begin{array}{l}\text { Attributes and } \\
\text { Functionalities }\end{array}$ & $\begin{array}{l}\text { Structures and } \\
\text { Interactions }\end{array}$ \\
\hline $\begin{array}{l}\text { - Search and browse } \\
\text { agents and resources } \\
\text { (e.g., text-search, menus, }\end{array}$ & $\begin{array}{l}\text { - New connections are } \\
\text { enabled among internal } \\
\text { agents (e.g., students }\end{array}$ \\
\hline
\end{tabular}

\begin{tabular}{|c|c|}
\hline $\begin{array}{l}\text { tagging, categories, } \\
\text { permanent URLs, and } \\
\text { automatically generated } \\
\text { 'home' pages that list } \\
\text { each agent's activity). }\end{array}$ & $\begin{array}{l}\text { browse e-portfolios to } \\
\text { learn about others) } \\
\text { - Existing connections } \\
\text { among agents are } \\
\text { strengthened (e.g., post } \\
\text { and comment history } \\
\text { gives a holistic view of a } \\
\text { student's knowledge and } \\
\text { opinions) } \\
\text { Resources are reused and } \\
\text { placed in new structures } \\
\text { (e.g., permanent URL } \\
\text { links to a post placed into } \\
\text { a new blog or in an } \\
\text { external resource) }\end{array}$ \\
\hline \multicolumn{2}{|c|}{ Design Principle: Aggregation ('push') } \\
\hline $\begin{array}{l}\text { Attributes and } \\
\text { Functionalities }\end{array}$ & $\begin{array}{l}\text { Structures and } \\
\text { Interactions }\end{array}$ \\
\hline $\begin{array}{l}\text { - Activity and content } \\
\text { from individual agents } \\
\text { and resource collections } \\
\text { is automatically collated } \\
\text { and made available as } \\
\text { feeds and placed into } \\
\text { search engines (e.g., } \\
\text { blogs are automatically } \\
\text { published through RSS, } \\
\text { site wide activity, e- } \\
\text { portfolio wire, each blog } \\
\text { is automatically search } \\
\text { engine optimized) }\end{array}$ & $\begin{array}{l}\text { - Resources are } \\
\text { updated regularly (e.g., } \\
\text { the wire showcases e- } \\
\text { portfolios updates which } \\
\text { encourage more updates) } \\
\text { - New resources or } \\
\text { resource collections are } \\
\text { formed (e.g., } \\
\text { departmental news RSS } \\
\text { feed is displayed on a } \\
\text { class blog) } \\
\text { - New connections are } \\
\text { formed outside existing } \\
\text { structures (e.g., 1. site- } \\
\text { wide feed is flat ignoring } \\
\text { course, major, graduation } \\
\text { year boundaries allowing } \\
\text { connections to be formed } \\
\text { based on mutual interest, } \\
\text { 2. course content is } \\
\text { found by a practitioner } \\
\text { searching the Internet) }\end{array}$ \\
\hline
\end{tabular}

The model is open. Access to e-portfolio content is not password protected nor controlled by the department, and is automatically posted on the Internet and search engine optimized (SEO). Each eportfolio is identified with a simple permanent URL for sharing on email, traditional resumes, and LinkedIn. This transforms the typical job application process, enabling employers to get on-demand access to rich information at a low time cost. Some managers are using e-portfolios as a substitute for initial screening to identify a smaller set of candidates for second-round interviews. 
Table 3. Design propositions

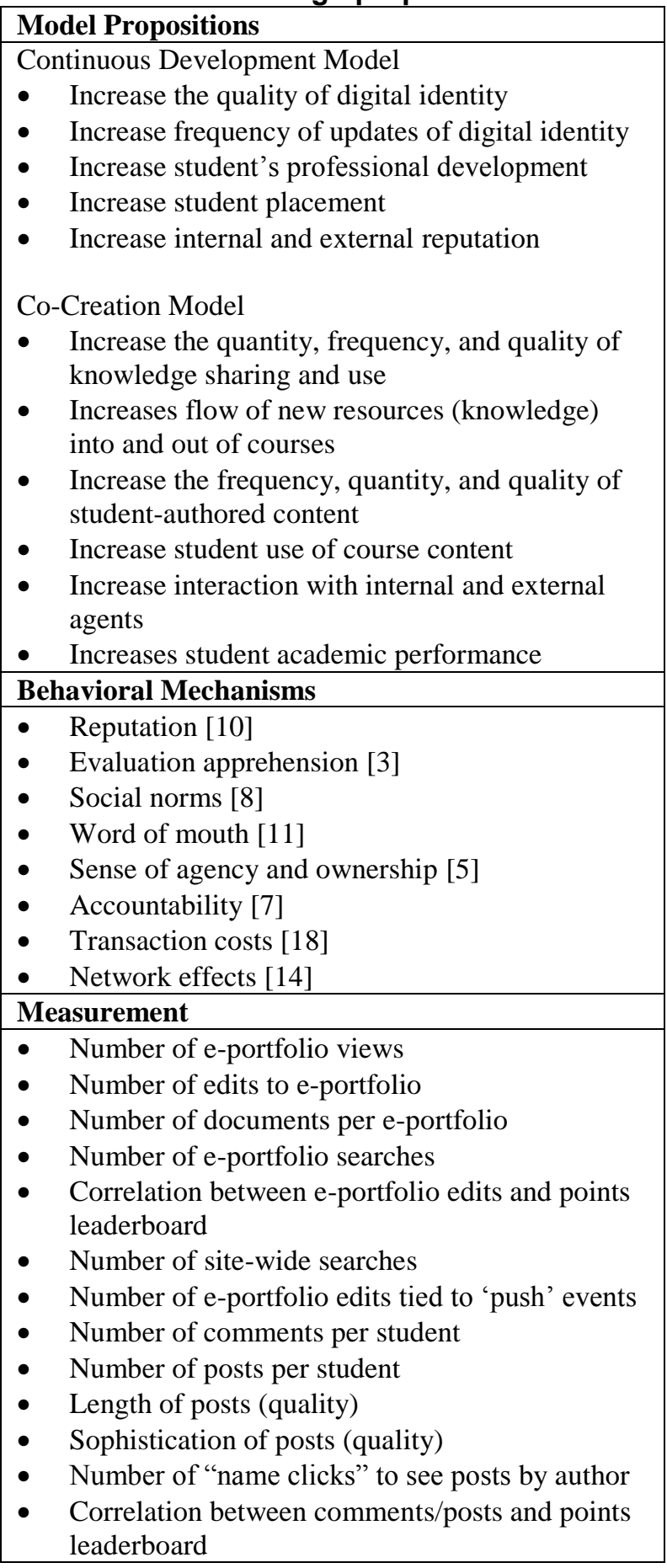

The model applies local and external visibility to motivate, legitimize, and empower. Students must have their site formally approved to be listed in the official e-portfolio search engine, providing employers with the filter of institutional legitimization. Unexpectedly, the search engine has become even more important in responding to employers' ad-hoc job leads. For example, an employer sends the following request: I am looking for an intern who can present well, with good analytical skills, and interest in healthcare. The community member uses the search to identify a short list, forms a recommendation, and then responds with links. The process transforms the time consuming task of asking for recommendations, verifying interest, and collecting resumes. The platform also empowers by pushing simple site analytics to each member. For example, a student who had a job interview the following morning noticed that there was traffic from the employer's network on a post about his internship. The student collected extra material and focused the interview on the internship. The employer was so impressed by his awareness that he was offered the job on the spot!

The check points, interactivity, internal and external visibility, and the flat and open structure transforms professional development into a continuous process instead of discrete and disconnected events. In the continuous development model, students realize early that their e-portfolio is their "always on" professional identity. As a result, career planning starts much earlier. For example, students are required to identify job interests to be listed in the search engine. For many, this is the first time that they have had to formally answer that question. Similarly, when students start their eportfolio, they realize that they have very little content. The best students immediately start seeking professional and intellectual development activities, especially, when they see other students with "better" content. Finally, since all changes show up on the site wide activity feed students start building their network early by checking on each other.

We originally envisioned leveraging the reach and flexibility (e.g., multimedia) of the web to create an electronic albeit static resume. What emerged instead is that e-portfolios were appropriated into many other activities, and the open, individual control, and discoverable and aggregation design principles of platform further fueled this appropriation, leading to a virtuous self-reinforcing cycle - a continuous development model that energizes the community at different parts of the value chain. The model plays a major role in achieving the institutional goal of placement. 


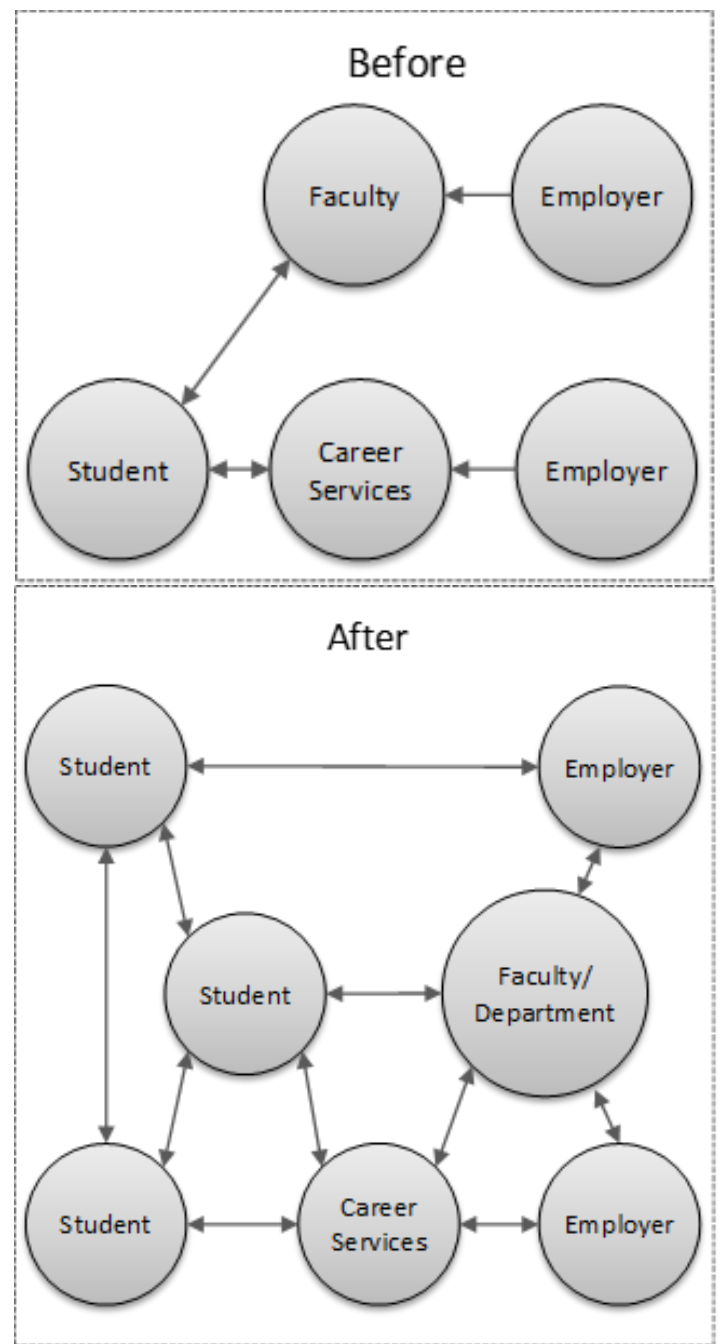

Figure 3. Continuous development model

\subsection{Co-creation model}

Courses are usually closed systems in which instructors disseminate pre-packaged knowledge, students receive that knowledge, and then demonstrate mastery. In the co-creation model students and faculty (a) co-create the course content and (b) bring in new and different sources of knowledge. Figure 4 contrasts the two approaches.

Co-creation involves two forms of content: (a) ideas, concepts, and facts that are newly developed or sourced from outside, and (b) discussion threads that reveal new insights about the pre-packaged content. Co-creation can be instantiated within, outside, and across courses. Within courses students are coauthors that are expected to actively bring in and post new content (e.g., relevant news). Outside the course the model is a magnet for relevant knowledge from experts. For example, a student news story about a critic of electronic medical records resulted in the critic finding the post and providing additional resources on the course site. Similarly, a data.gov member found course discussion on the U.S. Government's Open Data Initiative, and provided commentary and encouragement. Students formally engage with one another across courses to bring new energy into the original section. For example, students in one section receive credit for contributing content to another section, or are formally dependent in which one course produces content and the other consumes.

The co-creation model is a digital makeover of the traditional seminar; it enables, increases, and sustains interaction at a level and scope far beyond what has been achieved. Originally, we envisioned that the platform would increase instructor - student interaction (i.e., "class participation"). Instead, CAS theory highlights the role of multiple internal and external agents in providing, fueling, and legitimizing knowledge. The open nature of the site, along with the other design principles, work in conjunction to make these changes practically feasible.

The openness fuels a "tipping point" to increase and sustain fluid interaction that is different from a traditional bulletin board. The accessibility and ease of use brings in new content rather than the typical discussion of existing content. Second, students have a high degree of individual control over the course site. They have full authorship and responsibility over their posted content; the flat structure gives students' posts the same status and display attributes as the instructor's content - it is not in a different "area." Therefore, interaction can originate from and be led by students. They are motivated to engage others because when they respond, it publically validates their contribution within the course, across the community, and on the Internet.

Another outcome is that students leverage discovery mechanisms such as proudly linking their "marquee" posts to their e-portfolio, highlighting them for internal and external agents such as students and potential employers. Every post and comment to a course is aggregated on the site-wide activity feed, and can be also displayed in an area on the course's front page. Together, this can spark interest from and bring in new knowledge from external agents (e.g., students in different classes, faculty, and outside experts). 

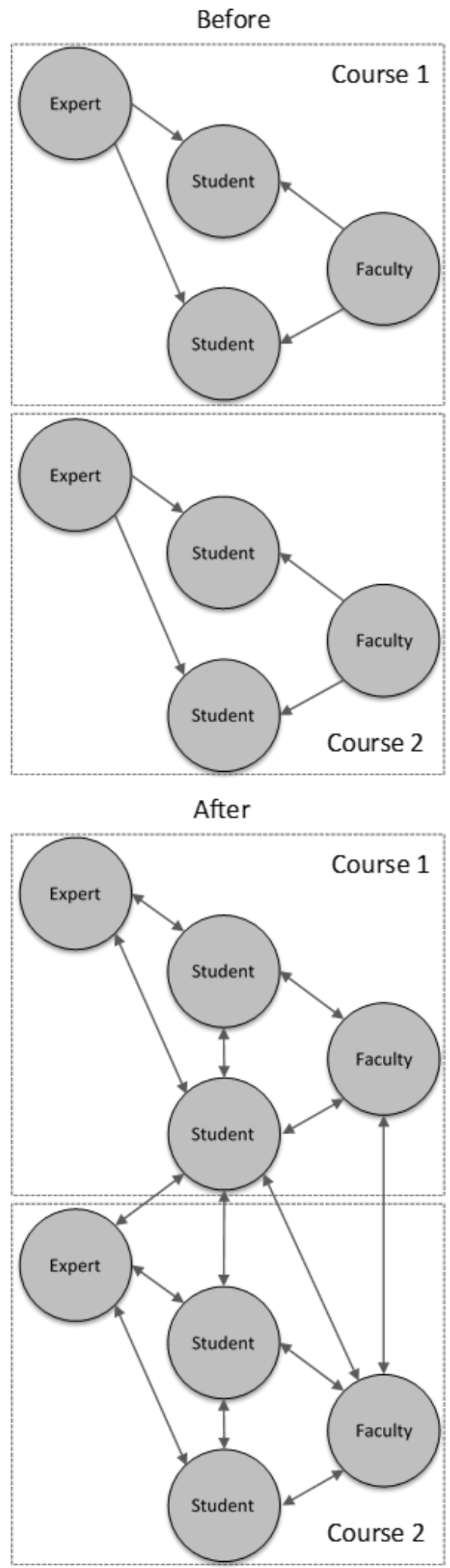

Figure 4. Co-creation model
Overall, the co-creation model (a) expands the pool of knowledge by providing opportunities to appropriate, generate, and validate knowledge with multiple agents, (b) external visibility is a powerful motivator to post well-thought out and interesting content, and (c) the sum of the interaction (i.e., all the posts and comments) provides contextualized and live materials rather than dry pre-packaged course content. Because students are co-authors in enacting the course, the model promotes abstraction and application. The model also influences the overall educational value chain by enhancing branding, recruiting, and retention. For example, openness showcases courses and vibrancy of engagement to prospective recruits, and because the content is aggregated and 'pushed' to the Internet it builds the brand and influences page rankings, while discovery creates shared ownership and a sense of community.

The co-creation model transforms traditional courses and boundaries where the instructor and students operate in a closed environment independent of the value chain. In the future, we see courses evolving into open knowledge brokerages that provide a nexus for interaction with internal and external agents.

\section{Future Research}

This analysis lays the groundwork for future research. A logical next step is to further validate the design propositions listed in table 2. While our explanation of the continuous development and cocreation models address the face validity of those propositions, they will need to be empirically tested using data for each of the measurement items (also in table 2). The data set will include Google Analytics, server log files, and text content from comments and posts, as well as institutional data such as career placement and academic performance metrics (i.e., average GPA). Examples of relationships we can test with this data include:

- Correlating the number of e-portfolio views and edits with placement rates and institutional reputation.

- Tracking the linguistic sophistication of comments and posts to see if there is improvement over time, and if so whether this improvement leads to greater academic performance.

- Examining cross-model effects, such as whether the number and sophistication of comments and posts within courses (co-creation) lead to improved placement outcomes (continuous development).

The ability to link design principles developed from our CAS analysis to measurable outcomes is significant. It provides a unique way to measure the 
efficacy of new systems within the context of higher education, where it is often difficult to assess whether an intervention has been effective.

\section{Conclusions}

Higher education is likely to change more over the next 10 years than it has in the last century. In order to adapt, institutions will need to look inward to understand how they really operate and what their strengths and vulnerabilities are in this emerging environment. In this paper, we have demonstrated how complex adaptive systems theory can facilitate this understanding of the interactions that take place within higher education and between the institution and its constituents.

The specific contributions of this paper include (1) Applying CAS to a new domain - higher education, (2) Applying CAS to design new IT enabled models, (3) Showing how IS can play a major role in both analyzing and designing IT to effect transformational change in higher education, and (4) Showing how a novel application of social media in the context of CAS theory changes structures and interactions.

The results of our analysis, including the design principles and the two models that employ them, have several broader applications. First, they provide a roadmap for building theory regarding how higher education can best leverage socially-enabled technologies. Second, the approach and guidelines used here can inform applications in other industries adopting social media collaboration platforms.

\section{Acknowledgements}

This paper is based on a previous non-academic magazine article: Mandviwalla, M., Schuff, D., Chacko, M. and Miller, L. (2013). Is That All There Is? Taking Education to New Levels in the Social Media Era. Change: The Magazine of Higher Learning, September 2013.

\section{References}

[1] Anderson, P., "Complexity theory and organization science”, Organization Science, 10(3), 1999, pp. 216-232.

[2] Christensen, C. M. and H.J. Eyring, The innovative university: Changing the DNA of higher education from the inside out. Jossey-Bass, San Francisco, USA, 2011.

[3] Cottrell, N.B., "Social Facilitation", In C. McClintock (ed.), Experimental Social Psychology, Holt, Rinehart \& Winston, New York, pp. 185-236.
[4] Delors, J. Learning: The treasure within. Report to UNESCO of the International Commission on Education for the Twenty-first Century. Unesco Publications, Paris, France, 1996.

[5] Gallagher, S., "Philosophical conceptions of the self: implications for cognitive science", Trends in Cognitive Sciences, 4, 2000, pp. 14-21.

[6] Grant Thornton, The state of higher education in 2012. Retrieved from: http://www.grantthornton.com/

[7] Greenberg, D., Education in America - A View from Sudbury Valley, Sudbury Valley School Press, Framingham, MA, 1992, pp. 60-62.

[8] Hackman, J.R., "Group influences on individuals in organizations", In M.D. Dunnette \& L.M. Hough (Eds.), Handbook of industrial and organizational psychology (Vol. 3). Consulting Psychologists Press, Palo Alto, CA, 1992, pp. 234-245.

[9] Holland, J. H., Hidden order: How adaptation builds complexity, Basic Books, New York, 1996.

[10] Klewes, J. and R. Wreschniok, Reputation Capital: Building and Maintaining Trust in the 21st Century, Springer, New York, 2010.

[11] Kozinets, R., de Valck, K., Wojnicki, A., and Wilner, J.S., "Networked Narratives: UnderstandingWord-ofMouth Marketing in Online Communities", Journal of Marketing, 74, 2010, pp. 71-89.

[12] Nan, N., "Capturing bottom-up information technology use processes: A complex adaptive systems model", MIS Quarterly, 35(2), 2011, pp. 505-532.

[13] Rouse, W.B., "Healthcare as a complex adaptive system", The Bridge, 38(1), 2008, pp. 17-25.

[14] Shapiro, C. and H. Varian, Information Rules. Havard Business School Press, Cambridge, MA, 1999.

[15] Smith, B. "Unconventional wisdom", Change: The Magazine of Higher Learning, 45(1), 2013, pp. 33-39.

[16] Vodanovich, S., D. Sundaram, and M. Myers, "Digital Natives and Ubiquitous Information Systems", Information Systems Research, 21(4), 2010, pp. 711-723.

[17] Watson, R., M. Boudreau, P. York, M. Greiner, and D. Wynn, "Opening the Classroom", Journal of Information Systems Education, 19(1), 2008.

[18] Williamson, O.E., "The Economics of Organization: The Transaction Cost Approach", The American Journal of Sociology, 87(3), 1981, pp. 548-577. 